\title{
Anti-melanogenic activity of Myristica fragrans extract against Aspergillus fumigatus using phenotypic based screening
}

Shanu Hoda ${ }^{1}$, Maansi Vermani ${ }^{1}$, Rajesh K. Joshi ${ }^{2}$ Jata Shankar ${ }^{3}$ and Pooja Vijayaraghavan ${ }^{1 *}$

\begin{abstract}
Background: Aspergillus fumigatus, an opportunistic fungal pathogen is associated with a wide array of diseases. It produces 1, 8-dihydroxy naphthalene (DHN) melanin that imparts greenish grey color to conidia and is an important virulence factor. It masks various molecular patterns associated with A. fumigatus and protects the fungus from host immune system. Myristica fragrans, enriched with secondary metabolites has been traditionally used for the treatment of infectious and inflammatory diseases. The present study was aimed to explore the antimelanogenic effect of $M$. fragrans extracts on A. fumigatus.
\end{abstract}

Methods: M. fragrans extracts (hexane, chloroform, methanol and ethanol) were prepared through polarity guided extraction. Phytochemical analysis was performed to detect the chemical constituents of the extracts. The minimum effective concentration (MEC) of the extracts against A. fumigatus melanin was determined by broth micro-dilution assay. Various virulence factors were assayed by spectrophotometric methods. Electron microscopic studies were performed to evaluate the effect of the hexane extract of $M$. fragrans on A. fumigatus cell surface morphology. The major active compounds of the extract were detected by gas chromatography-mass spectrometry (GC-MS). Docking was performed to study the interaction between the major identified compounds and the ketosynthase domain of polyketide synthase protein.

Results: The results indicated that the hexane extract of $M$. fragrans inhibited melanin production (76.09\%), reduced ergosterol content (83.63\%) and hydrophobicity of the cell $(72.2 \%)$ at the MEC of $0.078 \mathrm{mg} / \mathrm{mL}$. Altered conidial surface, disappearance of protrusions and absence of melanin layer on outer cell surface was observed in electron microscopy. Forty-two compounds were identified by GC-MS. The main constituents were identified as sabinene (12.2\%), linoleic acid (11.7\%), hexadecanoic acid (10.5\%), safrole (8.1\%) and elemicin (7.8\%). Docking studies revealed that hexadecanoic acid, its derivative compound cis-9-hexadecenal and isoeugenol have lower binding energy forming proper hydrogen bond with ketosynthase domain of polyketide synthase protein.

(Continued on next page)

\footnotetext{
*Correspondence: vrpooja@amity.edu

'Amity Institute of Biotechnology, Amity University Uttar Pradesh, Noida 201301, India

Full list of author information is available at the end of the article
}

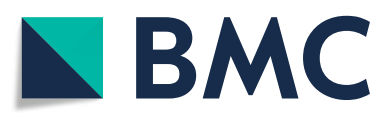

(c) The Author(s). 2020 Open Access This article is licensed under a Creative Commons Attribution 4.0 International License, which permits use, sharing, adaptation, distribution and reproduction in any medium or format, as long as you give appropriate credit to the original author(s) and the source, provide a link to the Creative Commons licence, and indicate if changes were made. The images or other third party material in this article are included in the article's Creative Commons licence, unless indicated otherwise in a credit line to the material. If material is not included in the article's Creative Commons licence and your intended use is not permitted by statutory regulation or exceeds the permitted use, you will need to obtain permission directly from the copyright holder. To view a copy of this licence, visit http://creativecommons.org/licenses/by/4.0/ The Creative Commons Public Domain Dedication waiver (http://creativecommons.org/publicdomain/zero/1.0/) applies to the data made available in this article, unless otherwise stated in a credit line to the data. 
(Continued from previous page)

Conclusion: The study concludes that the extract of M. fragrans has potential antifungal properties that can be explored in combination with available antifungals. This combination approach may be helpful for large number of patients suffering with A. fumigatus infections.

Keywords: Myristica fragrans spice, Aspergillus fumigatus, Melanin biosynthesis, Virulence, GC-MS

\section{Background}

Aspergillus species are the most prominent airborne fungal pathogens that account for various invasive and noninvasive infections based on the impaired immune system in humans $[1,2]$. They propagate by conidia which are ubiquitous and have high sporulating capacity. Once inhaled, they by-pass mucociliary clearance, germinate and produce septate vegetative mycelium that invades the lung tissue [3]. Among Aspergillus infections, more than $90 \%$ of pulmonary infections are caused by Aspergillus fumigatus [4]. Major pulmonary diseases due to $A$. fumigatus include allergic bronchopulmonary aspergillosis (ABPA), Aspergillus rhinosinusitis, chronic pulmonary aspergillosis, invasive aspergillosis, saprophytic aspergilloma and trachoebronchitis. These diseases manifestations can coexist in the same individual.

There are limited antifungal drugs available in the market to combat fungal infections. These drugs mainly target fungal cell wall (echinocandins) and ergosterol by either binding to ergosterol (polyenes) or inhibiting intermediary enzymes of ergosterol production (azoles and allylamines). These chemically synthesized drugs have several adverse effects such as anaphylaxis, chills, fever, headache, hepatotoxicities, nausea, neurotoxicity, and reproductive disorder [5]. These classical drugs are not cost effective [6]. Besides, the incidence of drug resistance in Aspergillus is increasing globally. Hence, there is an urgent need for affordable antifungal medications to improve the drug efficacy and reduce the side effects. The use of herbal medicines may be a suitable alternative that can open new avenues in antifungal treatment.

Various plant extracts have been reported to exhibit antibacterial, antifungal and insecticidal properties in vitro [7-11]. Spices contain various secondary metabolites such as flavonoids, phenolics, tannins, terpenes, quinines and are associated with antioxidant property. These bioactive compounds are involved in antimicrobial activity by the cell wall disruption, leakage of cellular components, fatty acid and phospholipid alteration [12].

Myristica fragrans is a dietary spice; belongs to the Myristicaceae family and is cultivated in the Banda Islands, Grenada, the Caribbean, South India, Sri Lanka, Malaysia, Sumatra, and Brazil [13]. The main constituents of $M$. fragrans have been found to be alkyl benzene derivatives (myristicin, elemicin, safrole etc.), terpenes, alpha-pinene, beta-pinene, myristic acid and trimyristin [14]. It contains about 2\% of lignans (diarylpropanoids), which are non volatile dimers of phenylpropanoid [15]. M. fragrans has been traditionally used for intestinal catarrh and colic, to stimulate appetite, control flatulence and also as an abortifacient $[16,17]$. It has been reported as an antidepressant with antioxidant and hepatoprotective role [18].

Multiple factors contribute to virulence of $A$. fumigatus including its versatile metabolism, thermo-tolerance, or the production of toxins and secondary metabolites like 1, 8-dihydroxy naphthalene (DHN) melanin [19]. DHNmelanin plays a major role in the protection of Aspergilli against harsh environmental conditions such as ultraviolet irradiation, reactive oxygen species and the host immune system [20]. Melanin has been shown to provide cell wall stability and structural rigidity [21]. It binds to antifungal drugs reducing their therapeutic efficacy. Time kill assay revealed that 71 and $79 \%$ of melanised yeast cells survived on exposure to $2 \mathrm{X}$ the MIC of amphotericin B and caspofungin, respectively [22]. Besides, melanin prevents intracellular killing of conidia by reducing luminal acidification and resisting phagolysosomal degradation $[1,3]$. The role of the conidial melanin in A. fumigatus has been studied by using pksP gene mutants $(\Delta \mathrm{pksP})$. The pksP gene encodes the first protein polyketide synthase (PKS) that catalyse the synthesis of heptaketide napthopyrone, the first step in the melanin biosynthesis pathway. The $\Delta$ pksP produce white color conidia whereas other gene mutants produced yellowish, reddish or brown colonies. It has been observed that melanized conidia masked various A. fumigatus associated molecular patterns to protect themselves from elimination whereas, the unpigmented white conidia were unable to quench reactive oxygen species (ROS) produced by human and animal granulocytes and were effectively eradicated by the host defense system $[1,23]$. Therefore, restraining the DHN-melanin biosynthesis through pksP gene/gene product inhibition may be considered as a novel drug target. To the best of author's knowledge, the role of $M$. fragrans as melanin inhibitor in A. fumigatus has not been studied till date. Thus, the present study was envisaged to evaluate the efficacy of $M$. fragrans extract as a melanin inhibitor in A. fumigatus.

\section{Methods}

\section{Fungal strains}

Aspergillus fumigatus (ATCC-46645) and its $\Delta \mathrm{pksP}$ strain were a kind gift from Prof. Axel Brakhage, Department of 
Molecular and Applied Microbiology, Lelbeniz Institute for Natural Product Research and Infection BiologyHKI, Germany. A. fumigatus strains were maintained by subculturing on Czapek Dox Agar (CzA) slants. The fungus was grown on $\mathrm{CzA}$ at $28 \pm 2{ }^{\circ} \mathrm{C}$ for 5 days to obtain conidial growth.

\section{Plant collection and extraction procedure}

The Myristica fragrans dried spice was procured from Spice Garden in Thekkady, Kerala, India and was authenticated by Dr. (Mrs) Sunita Garg, CSIR-Emeritus Scientist (Former Chief Scientist \& Head, Raw Materials Herbarium and Museum Delhi, CSIR-National Institute of Science Communication And Information Resources). A voucher specimen has been deposited in Raw Materials Herbarium and Museum Delhi and the deposition number is NISCAIR/RHMD/Consult/2018/3250-51.

Cleaned and dried spice (50 g) was ground using mortar and pestle to make a fine powder. It was then extracted with $200 \mathrm{~mL}$ hexane under constant shaking at room temperature for $72 \mathrm{~h}$. Thereafter, the extract was filtered and dried under vacuum using rotary evaporator. Further, the polarity guided extraction was done sequentially using chloroform, methanol and ethanol to yield hexane (8.54 g), chloroform (5.78 g), methanol $(2.88 \mathrm{~g}$ ) and ethanol $(1.88 \mathrm{~g})$ dried extracts. The dried extracts of $M$. fragrans were re-suspended in dimethyl sulfoxide (DMSO) to make the stock suspension of $100 \mathrm{mg} / \mathrm{mL}$ and stored at $4 \mathrm{oC}$ for further experiments. The prepared extracts were coded as $\mathrm{JaH}, \mathrm{JaC}$, JaM and JaE extract, respectively.

\section{Phytochemical analysis of extracts}

Preliminary qualitative phytochemical analysis of the $M$. fragrans extracts was carried out to detect the presence of saponins, tannins, terpenoids, carbohydrate, steroids, napthaquinones and flavonoids as per the protocol of Raaman [24].

\section{Determination of minimum effective concentration (MEC) of extracts for demelanization}

Minimum effective concentration with respect to the appearance of white colonies was determined by Clinical and Laboratory Standards Institute (CLSI) broth microdilution method [25]. The experiment was carried out in triplicates. Two-fold serial dilutions of the extracts were made in Czapek Dox Broth $(\mathrm{CzB})$ over a range to give final concentrations of $5.0-0.009 \mathrm{mg} / \mathrm{mL}$. One hundred microliters of $A$. fumigatus conidial suspension $0.8 \times 104$ conidia/mL was added to each well. Negative control comprised $\mathrm{CzB}$ only while the positive control was $\mathrm{CzB}$ and conidial suspension. The final volume in each well was $200 \mu \mathrm{l}$. The MECs of the extracts were detected after 5 days incubation at $28 \pm 2{ }^{\circ} \mathrm{C}$. MEC was defined as the lowest concentration of the extract that produced white colored conidia based on morphological appearance [25].

\section{Extraction, purification and UV- visible spectrophotometric analysis of melanin}

The isolation of cell-wall associated melanin from wild type conidia and treated conidia was performed as described by Rajagopal et al. [26]. The cultures were grown in CzA plates for 5 days at $28 \pm 2{ }^{\circ} \mathrm{C}$. The treated culture plates were supplemented with minimum effective concentration of the hexane extract $(\mathrm{JaH})$. Positive control plates were also prepared. Mycelial plug (1 cm diameter) was cut from the colonies grown on $\mathrm{CzA}$, boiled in $5 \mathrm{~mL}$ of distilled water for $5 \mathrm{~min}$ and then centrifuged for 5 min at $7000 \mathrm{rpm}$. The pellet was washed twice and melanin was extracted by autoclaving the pellet with $3 \mathrm{~mL}$ of $1 \mathrm{M} \mathrm{KOH}$. The extracted melanin was dried overnight at $20^{\circ} \mathrm{C}$ in a dehumified atmosphere. Further, acid hydrolysis was done to purify the extracted melanin by adding $5 \mathrm{~mL}$ of $7 \mathrm{M} \mathrm{HCL}$ in a sealed glass vial for $2 \mathrm{~h}$ at $100{ }^{\circ} \mathrm{C}$. After cooling, the pigment was washed thrice with distilled water, dried, and stored at $4{ }^{\circ} \mathrm{C}$. Extracted and dried pigment from solid culture was dissolved in 1 $\mathrm{M} \mathrm{KOH}$ and melanin was recorded as the absorption spectra at range of $200-600 \mathrm{~nm}$ using $1 \mathrm{M} \mathrm{KOH}$ as reference blank. The absorption spectra of the control and treated plates were determined and compared with the $\Delta$ pksP strain.

Melanin pigment isolated from the culture supernatant was assayed by harvesting the cells from culture broth by centrifugation. The pellet was dissolved in $1 \mathrm{M} \mathrm{KOH}$ and was vortexed properly. It was centrifuged at 7000 rpm for $5 \mathrm{~min}$ and the supernatant were purified by adding $7 \mathrm{M} \mathrm{HCl}$ and boiled for $2 \mathrm{~h}$, centrifuged and pellet was washed with distilled water. Extracellular melanin was assayed by dissolving the pellet in $1 \mathrm{M} \mathrm{KOH}$ and measuring the absorbance at $585 \mathrm{~nm}$ [27].

\section{Analysis of physio-chemical properties of melanin}

A. fumigatus was cultured on $\mathrm{CzA}$ with $\mathrm{JaH}$ extract (at MEC) and without the extract. The color patterns of the colonies were compared with the $\Delta$ pksP strain. The pigments extracted from the isolates were confirmed as melanin on the basis of their physical and chemical properties. Characterization of melanin is based on the solubility in $\mathrm{NaOH} / \mathrm{KOH}$, insolubility in water or organic solvents, decolorization by the oxidizing agents ( $\mathrm{H} 2 \mathrm{O} 2 / \mathrm{KMnO} 4)$ and precipitation by $1 \% \mathrm{FeCl} 3$ [28].

\section{Effect of JaH extract on conidia production in $A$. fumigatus}

The reduction in conidia formation was estimated spectrophotometrically at $530 \mathrm{~nm}$. Agar blocks $(1 \mathrm{~cm} 3)$ was excised from the 5 day old CzA plate using a sterile 
surgical blade and transferred to test tube. Phosphate buffer supplemented with $0.25 \%$ Tween- $20(5 \mathrm{~mL})$ was added to each tube, shaken vigorously and absorbance was measured at $530 \mathrm{~nm}$. The absorbance of control and the treated conidia were compared with respect to the $\Delta$ pksP strain.

\section{Ergosterol content estimation}

Ergosterol content was measured as described by Young et al. with minor modification [29]. Briefly, 5 days old mycelia were harvested by centrifugation at $2700 \mathrm{rpm}$, washed with sterile distilled water, dried and weighed. The dried pellet was transferred into sterile glass screw cap tubes and $3 \mathrm{~mL}$ of $25 \%$ of alcoholic $\mathrm{KOH}$ solution was added. The pellets were then incubated at $85^{\circ} \mathrm{C}$ in water bath for $1 \mathrm{~h}$. Tubes were kept at room temperature. Further, $1 \mathrm{~mL}$ of distilled water and $3 \mathrm{~mL}$ of $n$-octane was added, vortexed for $3 \mathrm{~min}$ and then allowed to stand for separating the organic layer, which was transferred to another clear screw cap tube and stored at $-20{ }^{\circ} \mathrm{C}$. For analysis, $200 \mu \mathrm{L}$ of the extracted sterol was mixed with $800 \mu \mathrm{L}$ absolute ethanol and was spectrophotometrically analyzed at $281.5 \mathrm{~nm}$ and $230 \mathrm{~nm}$. The conversion from optical density to ergosterol content was calculated as follows [29]:

$$
\begin{aligned}
\text { Ergosterol\% } & =\left[\left(\mathrm{A}_{281.5} / 290 \times \mathrm{F}\right) / \text { Weight of pellet }\right] \\
& -\left[\left(\mathrm{A}_{230} / 518 \times \mathrm{F}\right) / \text { Weight of pellet }\right]
\end{aligned}
$$

\section{$\mathrm{F}=$ Ethanol Dilution Factor}

\section{Cell surface hydrophobicity}

Hydrophobicity of the microbial cell suspension was assayed by two phase partitioning using hexadecane as the hydrocarbon phase described by Kennedy et al., with minor modification [30]. Briefly, conidia were harvested using phosphate buffer saline (PBS) and their absorbance was set to 0.30 at $630 \mathrm{~nm}$. Hexadecane $(500 \mu \mathrm{L})$ was then added and vortexed for $2 \mathrm{~min}$. The suspension was incubated for $10 \mathrm{~min}$ at room temperature for phase separation. The absorbance of the aqueous phase was then measured at $630 \mathrm{~nm}$ and was compared to the initial absorbance.

\section{Scanning electron microscopy (SEM)}

Conidia from 5 days old $A$. fumigatus cultures grown on CzA medium with and without JaH extract (at MEC) were harvested as described in earlier section. The conidia were fixed in $4 \%$ glutaraldehyde in PBS under vacuum for $24 \mathrm{~h}$. After washing, the cells were post-fixed with $1 \%$ osmium tetroxide for $60 \mathrm{~min}$ and dehydrated by passage through ethanol solutions of increasing concentration. The sample were then mounted on aluminium sheet and coated with gold-palladium alloy. The observations were made using a Zeiss SEM, MA EVO - 18 Special Edition [20].

\section{Transmission electron microscopy (TEM)}

A. fumigatus culture was grown in CzA medium with and without the $\mathrm{JaH}$ extract for 5 days. Conidia were harvested as described in earlier section, washed in and fixed overnight at room temperature with $2.5 \%$ glutaraldehyde with $0.1 \mathrm{M}$ sodium cacodylate buffer ( $\mathrm{pH}$ 7.4). Conidia were incubated for $1.5 \mathrm{~h}$ at $20^{\circ} \mathrm{C}$ in a solution of $4 \%$ formaldehyde- $1 \%$ glutaraldehyde in $0.1 \%$ PBS and then incubated in $2 \%$ osmium tetraoxide for $1.5 \mathrm{~h}$. Dehydration was accomplished by serial washing in graded ethanol solutions of $50-95 \%$ for $10 \mathrm{~min}$, followed by two final washes in $100 \%$ ethanol for $15 \mathrm{~min}$. The cells were embedded in Spurr's resin, sectioned onto nickel grids and examined on a JEOL 2100F transmission electron microscope to obtain micrographs [31].

\section{Chromatographic analysis}

The chemical constituents of the hexane extract of $M$. fragrans were analyzed using gas chromatography varian- 450 fitted with a fused silica capillary column TG-5 (30 m $\times$ $0.25 \mathrm{~mm}$ i.d., $0.25 \mu \mathrm{m}$ film thickness) [32, 33]. The oven temperature was programmed from 60 to $220^{\circ} \mathrm{C}$ at $3{ }^{\circ} \mathrm{C} /$ min, using nitrogen as carrier gas. The injector and the flame ionization detector (FID) temperature were set at 230 and $240{ }^{\circ} \mathrm{C}$, respectively. GC-MS analysis was employed using a Thermo Scientific Trace Ultra GC interfaced with a Thermo Scientific ITQ 1100 mass spectrometer which was fitted with a ZB-5 fused silica capillary column $(30 \mathrm{~m} \times 0.25 \mathrm{~mm} ; 0.25 \mu \mathrm{m}$ film thickness). The oven temperature range was programmed from 60 to $220^{\circ} \mathrm{C}$ at $3{ }^{\circ} \mathrm{C} / \mathrm{min}$ and helium was used as carrier gas at $1.0 \mathrm{~mL} / \mathrm{min}$ for analysis. The injector temperature was set

Table 1 Phytochemical screening of $M$. fragrans extracts

\begin{tabular}{llllllll}
\hline Name of extract & Tannins & Terpenoids & Flavonoids & Alkaloids & Steroids & Saponins & Carbohydrate \\
\hline $\mathrm{JaH}$ & ++ & ++ & - & ++ & +++ & - & + \\
$\mathrm{JaC}$ & + & + & - & + & ++ & + & + \\
$\mathrm{JaM}$ & + & + & - & ++ & + & - & ++ \\
$\mathrm{JaE}$ & ++ & + & - & + & + & - \\
\hline
\end{tabular}

$(+),(++)$ and $(+++)$ denotes presence of less, moderate and high amount of phytochemicals respectively, on the basis of color produced during the reaction. $(-)$ denotes absence of phytochemicals. JaH Hexane extract of $M$. fragrans, JaC Chloroform extract of M. fragrans, JaM Methanol extract of M. fragrans, JaE Ethanol extract of $M$. fragrans 


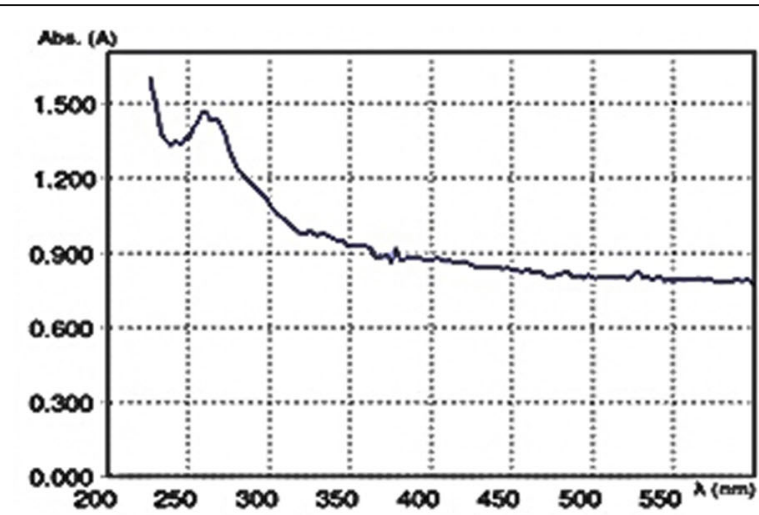

(A)

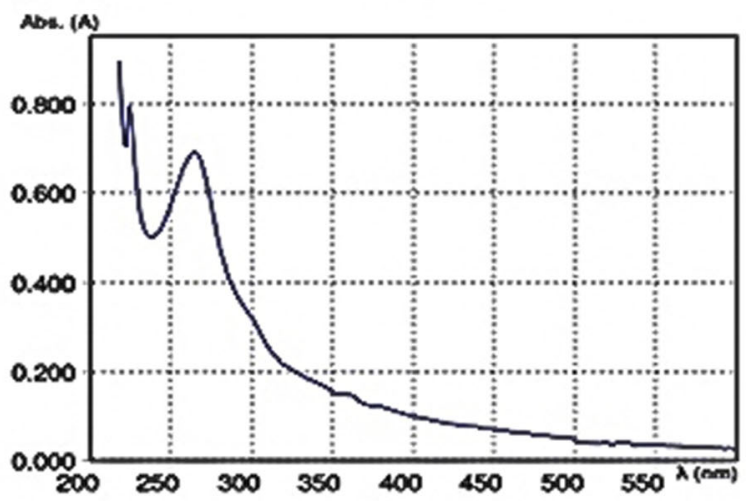

(B)

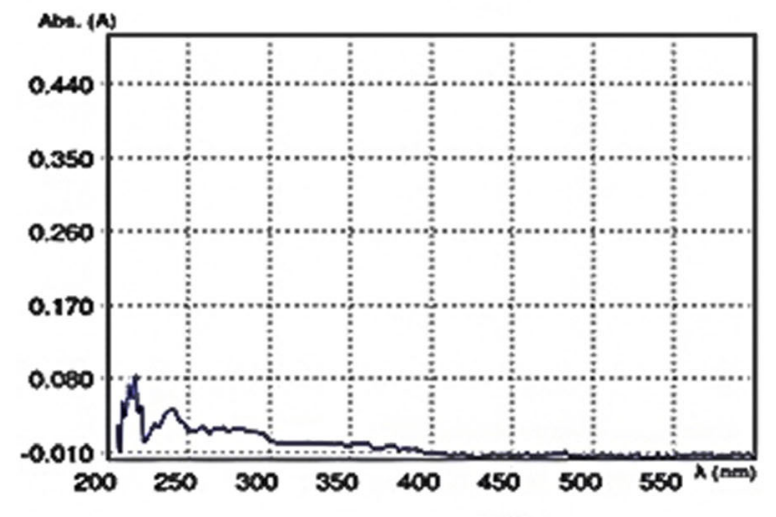

(C)

Fig. 1 UV-Vis Spectrum of melanin. The melanin was isolated from wild type A. fumigatus supplemented with $0.078 \mathrm{mg} / \mathrm{mL} \mathrm{JaH} \mathrm{extract,}$ without extract treatment as well as $\triangle p k s P$ strain. The melanin obtained from wild type (a) and JaH extract treated A. fumigatus (b) shows typical peak observed in UV range, gradually decreasing with the increase in wavelength whereas, no such characteristic peak observed in $\triangle \mathrm{pks} P$ strain (c)

at $230{ }^{\circ} \mathrm{C}$, and the injection volume was $0.1 \mu \mathrm{L}$ in $n$-hexane, with a split ratio of 1:50. MS was taken at $70 \mathrm{eV}$ with a mass range of $\mathrm{m} / \mathrm{z} 40-450[34,35]$. Identification of constituents was done on the basis of retention index (RI), determined with reference to homologous series of $n$ - alkanes $\mathrm{C}_{8}-\mathrm{C}_{25}$ under identical experimental conditions, by comparing with the MS literature data [36] and coinjection of commercial samples from Sigma-Aldrich, India ( $\geq 98 \%$ purity). The relative amounts of individual components were calculated based on the GC peak area (FID response) without using a correction factor.

\section{Docking study through protein ligand interaction}

Molecular docking study was carried out with AutoDock 4 for ketosynthase (KS) domain of polyketide synthase (PKS) enzyme/protein. The KS domain was searched in NCBI Conserved Domain Search tool and then domain location in the protein sequence was found using FASTA. The Structure of KS was retrieved using software SWISS MODEL (Fig. 6b). The structure of compounds (ligand molecules) was retrieved from PubChem (https://pubchem.ncbi.nlm.nih.gov/; Fig. 6a). The Lamarckian genetic algorithm was used in AutoDock 4 to perform the automated molecular dockings with default parameters. The number of run was set to 50 and the lowest binding energy conformation was selected for LigPlot analysis.

\section{Statistical analysis}

The statistical analysis was conducted using one-way ANOVA to compare the results of melanin estimation, conidiation, $\mathrm{CSH}$ and ergosterol assay for extract treated culture with wild type, drug treated and $\Delta p k s P$ strain. All experiments were conducted in technical and biological triplicates. The statistical analysis was performed using Graphpad Prism software 8.0.2.263 version and Microsoft Excel. $p<0.05$ was considered statistically significant.

\section{Results}

\section{Phytochemical analysis of extracts}

The phytochemical tests revealed the presence of steroids, carbohydrate, tannins, alkaloids and terpenoids in the $M$. fragrans extracts (Table 1). However, flavonoids and saponins were not present. JaH extract showed the highest amount of steroids, tannins and terpenoids which were evaluated on the basis of the color production in the respective phytochemical test.

\section{Determination of minimum effective concentration}

White colonies of $A$. fumigatus were observed in the wells containing the extract whereas control wells showed greenish grey conidia. The minimum effective concentration was determined as the lowest concentration of the $M$. fragrans extracts showing pigmentless conidial growth as compared to greenish grey wild type conidia. The JaH extract was effective for melanin inhibition at $0.078 \mathrm{mg} / \mathrm{mL}$ concentration whereas other extracts inhibited melanin formation at higher concentration. The MEC for JaC and JaM was $1.25 \mathrm{mg}$ / 


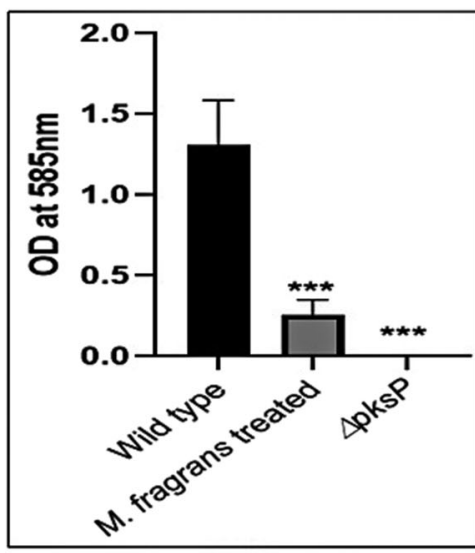

(A)

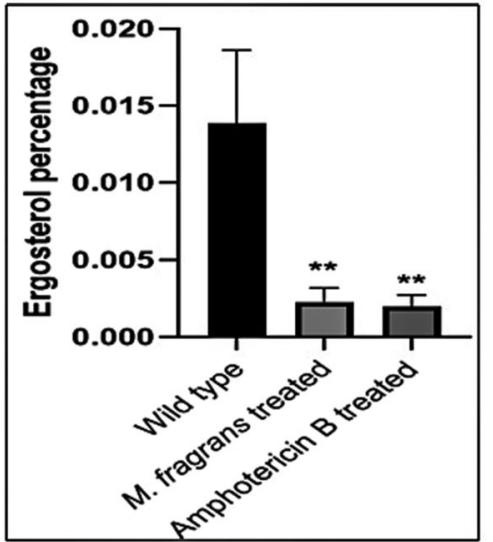

(C)

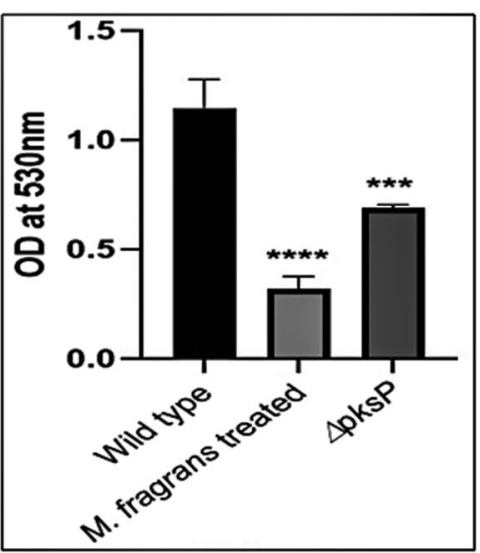

(B)

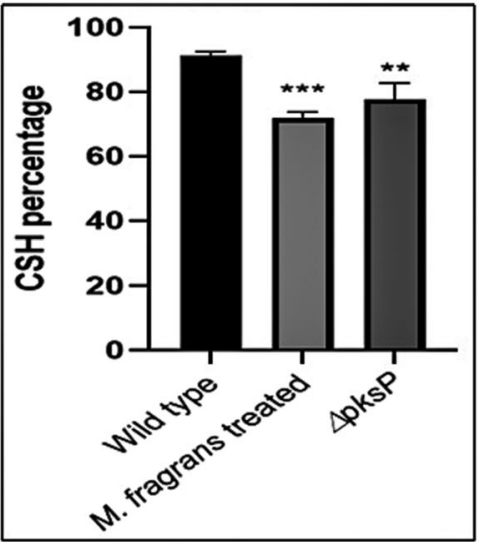

(D)

Fig. 2 Evaluation of the physical properties of the conidial surface. The $\triangle p k s P$ strain (negative control) and wild type A. fumigatus with JaH extract $0.078 \mathrm{mg} / \mathrm{mL}$, Amp B $0.012 \mathrm{mg} / \mathrm{mL}$ (drug control) and without any treatment (positive control) were grown on Czapek medium for 5 days at $28^{\circ} \mathrm{C}$. A. fumigatus extract treated culture showed reduced melanin content (a), decreased conidia formation (b), altered membrane surface due to reduction in ergosterol content (c) and cell surface hydrophobicity (d) analogous to the $\triangle p k s P$ strain and Amp B treated culture. $p<0.05$ was considered statistically significant

$\mathrm{mL}$ and for JaE was $2.50 \mathrm{mg} / \mathrm{mL}$. Therefore, JaH extract was selected for further experiments.

\section{UV- visible spectrophotometric analysis of melanin}

Melanin was extracted from wild type, JaH extract treated cultures and $\Delta$ pksP strain. The spectral study of melanin from both wild type and treated cultures showed a characteristic peak in the UV region 200-260 nm (Fig. 1). The light absorbed by melanin was maximum in the UV region and decreased gradually as the wavelength increased. The $\Delta$ pksP strain showed no characteristic peak depicting the absence of melanin.

The extracellular melanin content was estimated by spectrophotometric method at $585 \mathrm{~nm}$. The results indicated reduction in melanin content after treatment as compared to the solvent control plates. Melanin content was reduced by $76.09 \%$ after treatment with the extract as compared to control whereas $99.8 \%$ reduction in the melanin content was estimated in $\Delta$ pksP culture (Fig. 2a; $p<0.05)$.

\section{Physical and chemical properties of melanin}

The culture plates were phenotypically visualized and white colonies were observed after the extract treatment. Figure $3 \mathrm{~b}$ shows the effect of $M$. fragrans extract on melanin inhibition in A. fumigatus at MEC as compared to wild type colonies (Fig. 3a) and $\Delta$ pksP (Fig. 3c). The extracted pigment was characterized on the basis of physico-chemical tests. The extracted pigment was soluble in $\mathrm{NaOH}$ and $\mathrm{KOH}$ whereas, insoluble in water or organic solvents like chloroform, ethyl acetate, alcohol and acetone. The pigment was decolorized by the oxidizing agents $\mathrm{H} 2 \mathrm{O} 2$ and $\mathrm{KMnO} 4$ and precipitated by $1 \% \mathrm{FeCl} 3$. 


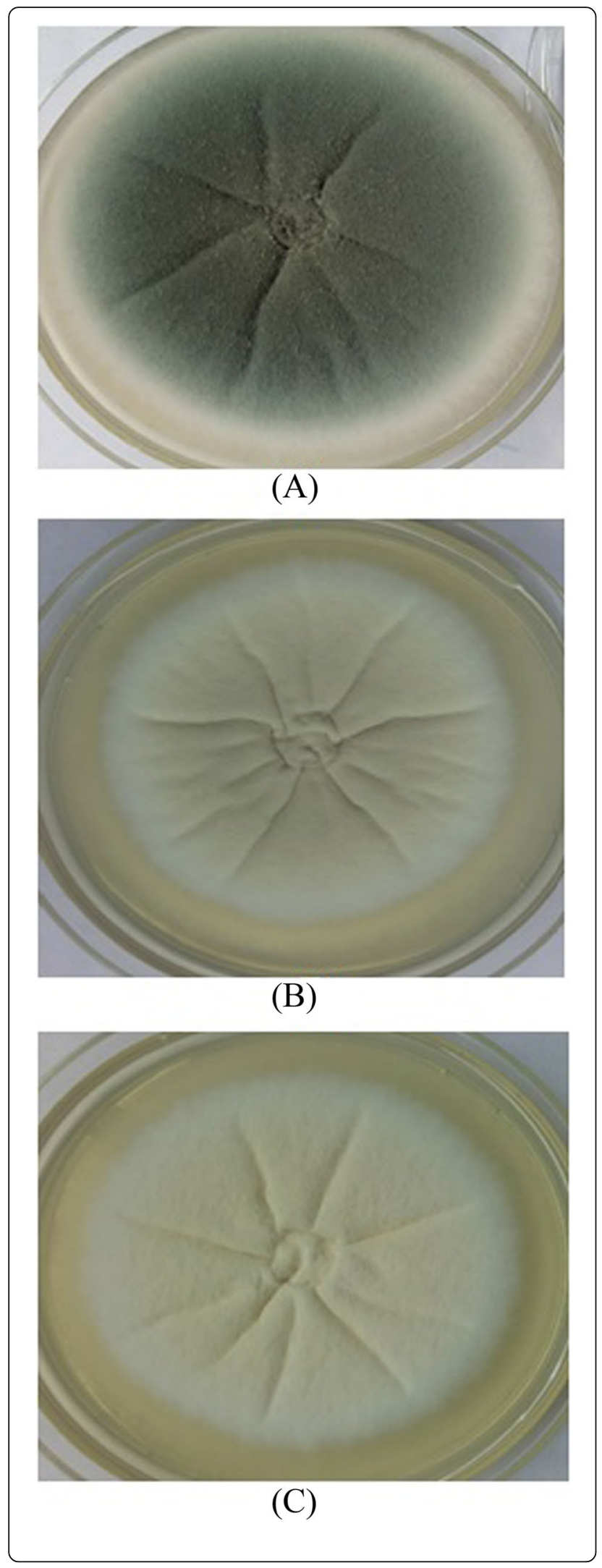

Fig. 3 Effect of extract on A. fumigatus grown on Czapek medium. The wild type strain of $A$. fumigatus was grown on Czapek agar, supplemented (b) or not (a) with $0.078 \mathrm{mg} / \mathrm{mL}$ of JaH extract for 5 days at $28^{\circ} \mathrm{C}$. The colour of the colonies obtained in the presence of $\mathrm{JaH}$ is similar to that of colonies of $\triangle p k s P$ strain grown on Czapek medium (c)

\section{Effect of JaH extract on conidia production in $A$. fumigatus}

Conidia formation was spectrophotometrically measured at $530 \mathrm{~nm}$. It was observed that Conidia formation reduced by $72.1 \%$ after treatment with the extract of $M$. fragrans whereas $\Delta \mathrm{pksP}$ culture showed $39.78 \%$ conidial reduction (Fig. $2 \mathrm{~b} ; p<0.05$ ).

\section{Ergosterol content estimation}

A. fumigatus hyphae were analyzed for the ergosterol content with and without extract. Amphotericin B (Amp B), a known inhibitor of ergosterol was used as positive control. A reduction of 83.63 and $85.02 \%$ was found in the ergosterol content after treatment with extract and Amp B, respectively in comparison to control group (Fig. 2c; $p<0.05$ ).

\section{Cell surface hydrophobicity}

$\mathrm{CSH}$ was assessed by two-phase partitioning with hexadecane as the hydrocarbon phase. A decrease in the $\mathrm{CSH}$ for both treated and $\Delta$ pksP culture was observed as compared to the control wild type greenish grey conidia. The treated conidia showed $72.20 \%$ decrease in $\mathrm{CSH}$ and $\Delta$ pksP culture exhibited $77.79 \%$ (Fig. $2 \mathrm{~d} ; p<0.05$ ) $\mathrm{CSH}$ reduction. This decrease in hydrophobicity was also observed during the preparation of conidial suspensions.

\section{Scanning electron microscopy}

The cell surface morphology of wild type conidia, $\Delta \mathrm{pksP}$ and the extract treated $A$. fumigatus conidia were analyzed and compared by SEM. The wild type conidia showed echinulate surface. The $\Delta$ pksP revealed smooth conidial surface with complete absence of any protrusions. The extract treated conidia also revealed smooth conidial surface devoid of any ornamentation (Fig. 4a-c).

\section{Transmission electron microscopy}

Lateral section of the wild type, $\Delta \mathrm{pksP}$ and treated conidia was visualized by TEM. The lateral section of the wild type conidia showed thick electron dense inner layer indicating the presence of melanin in between the membrane (Fig. 5a). In comparison to the wild type conidia, both $\Delta$ pksP and extract treated conidial section showed visible clear inner surface. There was an absence of electron dense layer. The two clear thin layers were also devoid of cell surface ornamentations (Fig. 5b-c). 


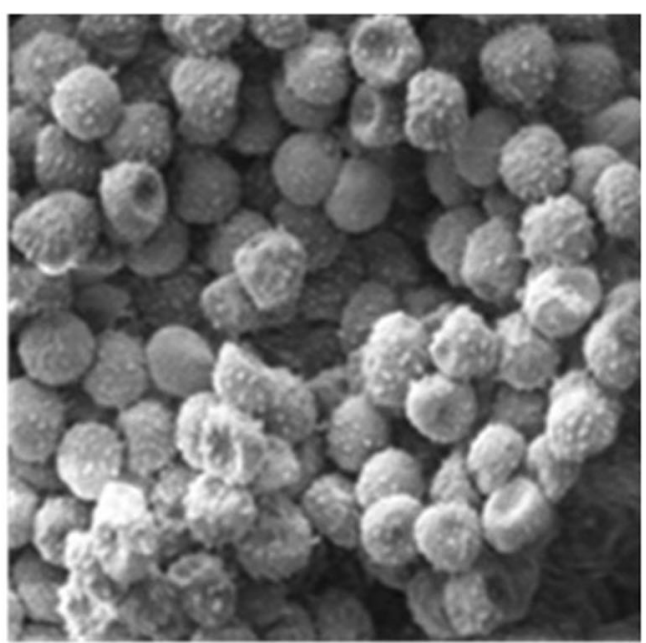

(A)

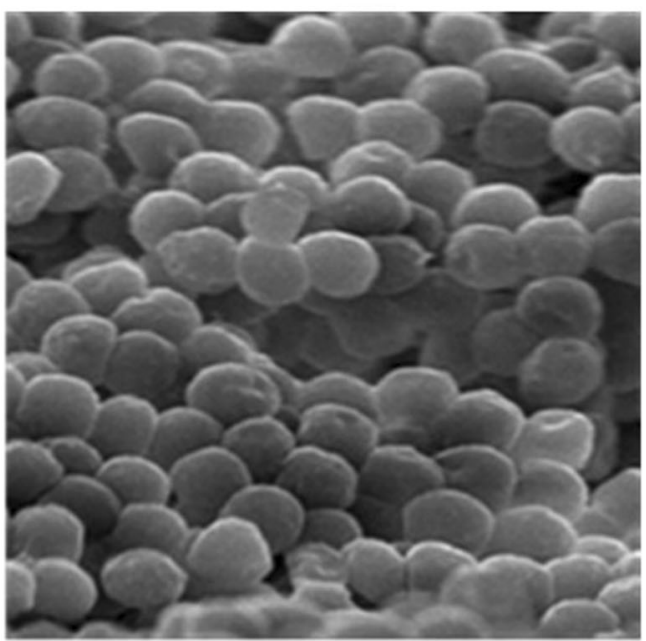

(B)

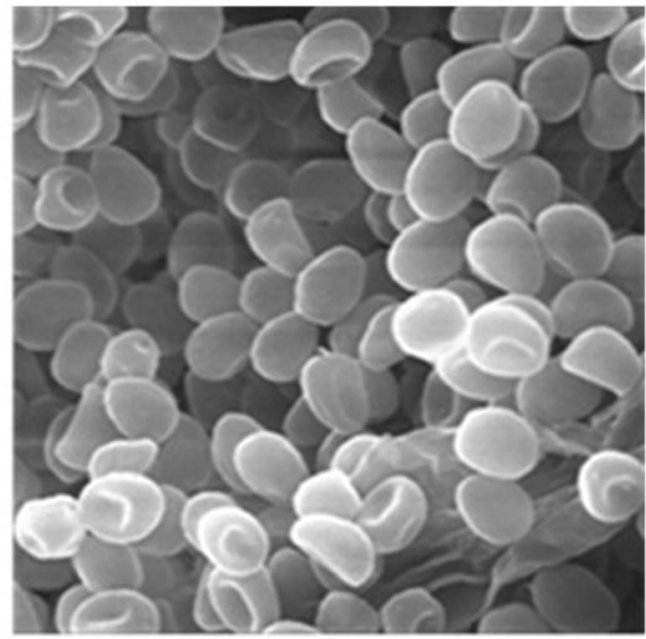

(C)
Fig. 4 Visualisation of the conidial surface by scanning electron microscopy. Micrograph of conidia from 5- days- old cultures of wild type A. fumigatus (a), cultivated in the presence of JaH extract 0.078 $\mathrm{mg} / \mathrm{mL}$ and $\triangle \mathrm{pks} P$ strain (c). Magnification of (a) and (b) is $9.1 \mathrm{KX}$, of (c) is $5.6 \mathrm{KX}$ and scale corresponds to $2 \mu \mathrm{m}$

\section{Chromatographic analysis}

Forty-two compounds were characterized and identified according to their mass spectra and their relative retention indices determined on a non-polar stationary phase capillary column, comprising $97.1 \%$ of the total extract. The identified compounds are listed in Table 2 in elution order from the ZB-5 column, along with the percentage composition of each component and its refractive index. The main constituents were identified as sabinene (12.2\%), linoleic acid (11.7\%), hexadecanoic acid $(10.5 \%)$, safrole $(8.1 \%)$, elemicin $(7.8 \%)$, myristicin (6.7\%) and $\beta$-pinene (6.5\%). The extract was found to be rich in monoterpene hydrocarbons (36.4\%), followed by long chain oxygenated hydrocarbons (29.5\%), phenylpropanoids $(17.5 \%)$, oxygenated monoterpenes $(10.9 \%)$, sesquiterpene hydrocarbons (2.4\%), oxygenated diterpene $(0.3 \%)$ and diterpene hydrocarbon $(0.1 \%)$.

\section{Protein ligand interaction}

The LigPlot analysis depicted that despite of having low binding energy, elemicin $(-5.35 \mathrm{Kcal} / \mathrm{mol})$ was stabilized solely by hydrophobic interaction and formed no hydrogen bond with the amino acid residues of KS domain of PKS protein. The lower binding energy was observed in hexadecanoic acid $(-4.19 \mathrm{Kcal} / \mathrm{mol})$, its derivative compound cis-9-hexadecenal $(-5.71 \mathrm{Kcal} / \mathrm{mol})$ and isoeugenol $(-6.14 \mathrm{Kcal} / \mathrm{mol})$. They formed both hydrogen bonds and hydrophobic interactions with PKS. Hexadecanoic acid and cis-9-hexadecenal formed proper hydrogen bonding at Asn422 whereas in isoeugenol Ser267, His277 and Asn422 was contact residue within the docking site (Fig. 6c). Cross comparing the interaction revealed that all the test ligands interacted at Asn422 residue of KS domain of PKS.

\section{Discussion}

Herbs and spices have been used as dietary supplements and traditional medicines since ages. Previous study by Mc Fadden et al. reported that crude spice extracts exhibit good antifungal activity and the probable mechanism involves the inhibition of various cellular processes, augmenting the membrane permeability and finally, leading to leakage of ions from the cells [37]. $M$. fragrans is a spice widely used as flavoring agent in food industries. In the present study, polarity guided extraction of $M$. fragrans was done using hexane, chloroform, methanol and ethanol based on their increasing polarity. It has been reported that the type of solvent used for extract 


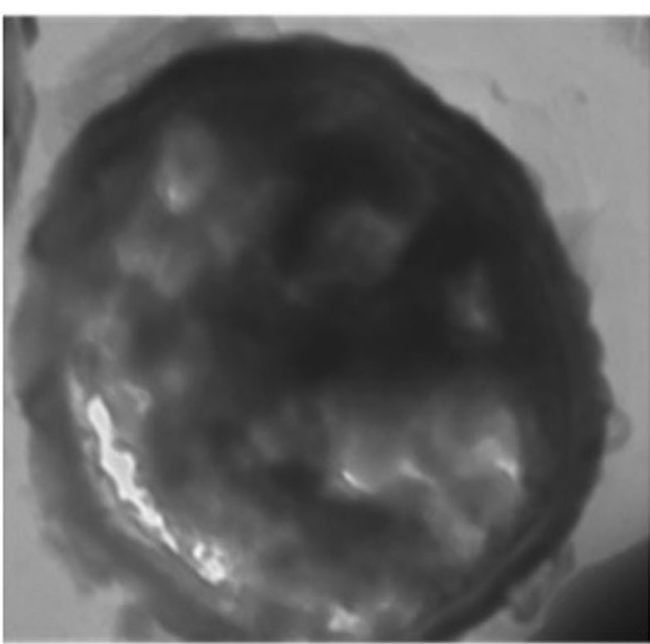

(A)

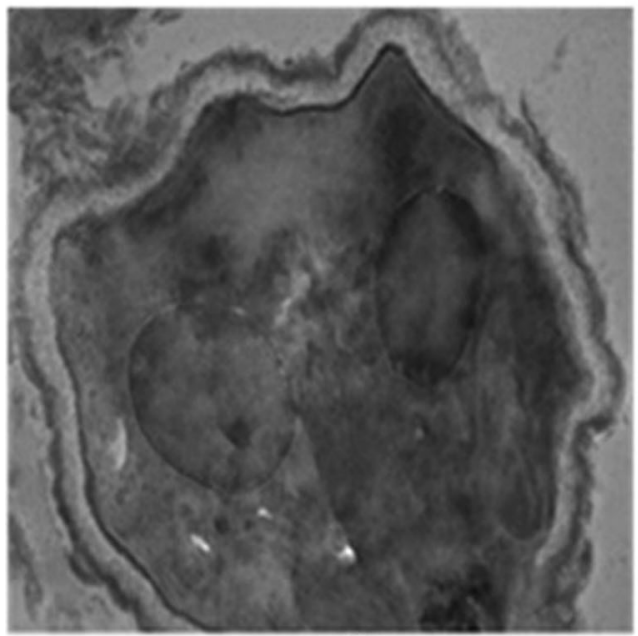

(B)

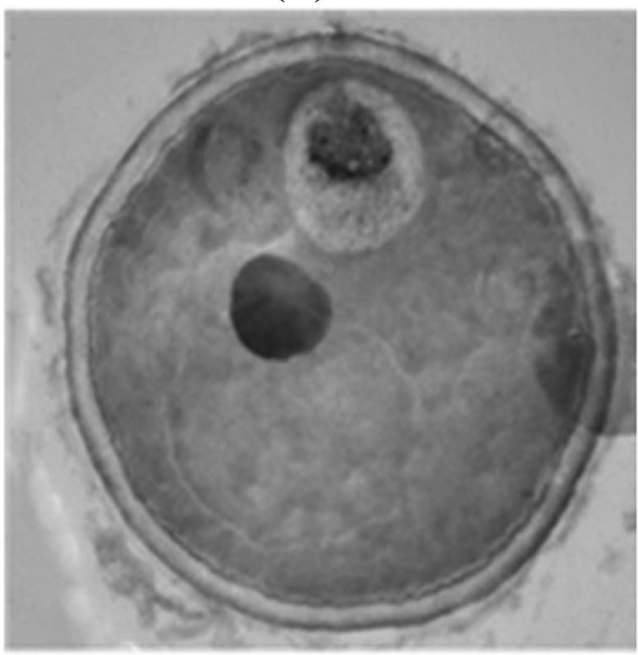

(C)
Fig. 5 Ultrastructure of the conidial wall as visualised by transmission electron microscopy. Conidia from 5- days- old cultures of wild type A. fumigatus (a), cultivated in the presence of JaH extract $0.078 \mathrm{mg} / \mathrm{mL}$ and $\triangle \mathrm{pks} P$ strain (c) were processed for ultrastructural examination of their cell wall. Conidia from wild type $A$. fumigatus shows dense layer around cell wall (a), whereas $A$. fumigatus cultivated in the presence of JaH extract (b) are relatively smooth surfaced similar to that of the $\triangle \mathrm{pksP}$ strain (c)

preparation impacts the antimicrobial activity because even after the solvents were removed from extracts by evaporation; chemical compounds extracted using various solvents were different. In the present study JaH extract exhibited best result which coincides with the study reported by Witkowska et al. [12]. Hexane being non polar solvent breaks the hydrophobic barriers and hexane extract contains maximum lipophilic metabolites lignin, wax, lipids, sterols and terpenoids [38-40]. Thus, hexane extract was used for further studies.

The commonly reported phytochemical constituents of $M$. fragrans are volatile substances, terpenoids, phenolics, lignin compounds, protein, mucilage and starch [41]. The present study confirmed the presence of alkaloids, steroids, tannins and terpenoids in $M$. fragrans extract. However, Iyer et al. reported the absence of terpenoids in their extracts [42]. This variation may be attributed to the plant sources, climatic conditions and the extraction methodology [43].

While the phytochemical constituents of $M$. fragrans have been extensively studied for its antifungal effect [42, 44-47], the melanin inhibiting potential has not been studied till date. The present work aimed at evaluating the antifungal effect of $M$. fragrans extract as a melanin inhibitor against $A$. fumigatus. The role of DHN-melanin as an important virulent factor has been broadly described [1, 3, 20, 28]. It has also been reported that mutation in each gene of the DHN-melanin biosynthesis cluster produced different colored colony. $\Delta p k s P$ $A$. fumigatus produced white avirulent colonies, whereas deletion of other genes of DHN-melanin cluster produced grey, reddish pink and brown conidia [1]. Among all extracts used, JaH extract showed melanin inhibition at minimum concentration against $A$. fumigatus. The culture plates with JaH extract at MEC were seen to be white in color as compared to the control wild type culture which was greenish grey (Fig. 3). Hence, it was hypothesized that the target of the extract is either pksP gene or its translational product which remains to be clarified.

Melanin was extracted from A. fumigatus after JaH extract treatment as well as wild type culture. The extracted pigment showed positive result for the chemical tests used for fungal melanin diagnosis [28]. The result depicted that the absorbance declined as the wavelength 
Table 2 Chemical constituents of JaH extract

\begin{tabular}{|c|c|c|c|}
\hline Compound & $\mathrm{Rl}$ & Area \% & Mode of Identification \\
\hline$\overline{a-T h u j e n e}$ & 897 & 1.4 & $\mathrm{Rl}, \mathrm{MS}$ \\
\hline a-Pinene & 903 & 3.8 & $\mathrm{RI}, \mathrm{MS}, \mathrm{Cl}$ \\
\hline a-Fenchene & 913 & 0.3 & $\mathrm{Rl}, \mathrm{MS}$ \\
\hline Camphene & 914 & $\mathrm{t}$ & $\mathrm{Rl}, \mathrm{MS}$ \\
\hline Sabinene & 934 & 12.2 & $\mathrm{Rl}, \mathrm{MS}$ \\
\hline$\beta$-Pinene & 937 & 6.5 & $\mathrm{Rl}, \mathrm{MS}$ \\
\hline Myrcene & 947 & 1.7 & $\mathrm{Rl}, \mathrm{MS}, \mathrm{Cl}$ \\
\hline a-Phellandrene & 960 & 1.8 & $\mathrm{Rl}, \mathrm{MS}, \mathrm{Cl}$ \\
\hline$\delta$-3-Carene & 966 & 0.5 & $\mathrm{Rl}, \mathrm{MS}$ \\
\hline$a$-Terpinene & 972 & 0.8 & $\mathrm{Rl}, \mathrm{MS}, \mathrm{Cl}$ \\
\hline o-Cymene & 979 & 0.3 & $\mathrm{Rl}, \mathrm{MS}$ \\
\hline Limonene & 983 & 4.5 & $\mathrm{Rl}, \mathrm{MS}, \mathrm{Cl}$ \\
\hline 1,8-Cineole & 986 & 0.2 & RI, MS. Cl \\
\hline$\gamma$-Terpinene & 1013 & 1.1 & $\mathrm{Rl}, \mathrm{MS}$ \\
\hline cis-Sabinene hydrate & 1023 & 0.7 & $\mathrm{Rl}, \mathrm{MS}$ \\
\hline Terpinolene & 1045 & 1.5 & $\mathrm{RI}, \mathrm{MS}, \mathrm{Cl}$ \\
\hline trans-Sabinene hydrate & 1057 & 0.8 & $\mathrm{Rl}, \mathrm{MS}$ \\
\hline 1,3,8-p-Menthatriene & 1071 & $\mathrm{t}$ & $\mathrm{Rl}, \mathrm{MS}$ \\
\hline Terpin-4-ol & 1148 & 0.8 & $\mathrm{Rl}, \mathrm{MS}, \mathrm{Cl}$ \\
\hline a-Terpineol & 1163 & 0.3 & $\mathrm{RI}, \mathrm{MS}, \mathrm{Cl}$ \\
\hline Sabinene hydrate acetate & 1241 & $\mathrm{t}$ & $\mathrm{Rl}, \mathrm{MS}$ \\
\hline Safrole & 1288 & 8.1 & $\mathrm{Rl}, \mathrm{MS}$ \\
\hline$\delta$-Elemene & 1354 & 0.3 & $\mathrm{Rl}, \mathrm{MS}$ \\
\hline Eugenol & 1364 & $\mathrm{t}$ & $\mathrm{RI}, \mathrm{MS}, \mathrm{Cl}$ \\
\hline a-Copaene & 1386 & 0.3 & $\mathrm{Rl}, \mathrm{MS}$ \\
\hline$\beta$-Cubebene & 1403 & $\mathrm{t}$ & $\mathrm{RI}, \mathrm{MS}$ \\
\hline Methyl eugenol & 1420 & 1.3 & $\mathrm{RI}, \mathrm{MS}, \mathrm{Cl}$ \\
\hline$\beta$-Caryophyllene & 1437 & 0.7 & $\mathrm{RI}, \mathrm{MS}, \mathrm{Cl}$ \\
\hline (E)-Isoeugenol & 1471 & 0.5 & $\mathrm{RI}, \mathrm{MS}, \mathrm{Cl}$ \\
\hline a-Humulene & 1477 & 0.7 & $\mathrm{Rl}, \mathrm{MS}$ \\
\hline$\gamma$-Muurolene & 1503 & $\mathrm{t}$ & $\mathrm{Rl}, \mathrm{MS}$ \\
\hline Germacrene D & 1508 & 0.4 & $\mathrm{Rl}, \mathrm{MS}$ \\
\hline (E)-Methyl isoeugenol & 1527 & 0.8 & $\mathrm{Rl}, \mathrm{MS}$ \\
\hline Myristicin & 1556 & 6.7 & $\mathrm{RI}, \mathrm{MS}, \mathrm{Cl}$ \\
\hline Elemicin & 1595 & 7.8 & $\mathrm{Rl}, \mathrm{MS}$ \\
\hline (E)-Isoelemicin & 1695 & 0.4 & $\mathrm{Rl}, \mathrm{MS}$ \\
\hline Hexadecanoic acid & 2003 & 10.5 & $\mathrm{RI}, \mathrm{MS}, \mathrm{Cl}$ \\
\hline Ethyl hexadecanoate & 2028 & 0.4 & $\mathrm{Rl}, \mathrm{MS}$ \\
\hline 13-epi-manool oxide & 2044 & 0.3 & $\mathrm{RI}, \mathrm{MS}$ \\
\hline Kaurene & 2065 & 0.1 & $\mathrm{Rl}, \mathrm{MS}$ \\
\hline Linoleic acid & 2150 & 6.9 & $\mathrm{RI}, \mathrm{MS}$ \\
\hline Oleic acid & 2156 & 11.7 & $\mathrm{RI}, \mathrm{MS}$ \\
\hline \multicolumn{2}{|l|}{ Monoterpene hydrocarbons } & 36.4 & \\
\hline \multicolumn{2}{|l|}{ Oxygenated monoterpenes } & 10.9 & \\
\hline \multicolumn{2}{|l|}{ Sesquiterpene hydrocarbons } & 2.4 & \\
\hline \multicolumn{2}{|l|}{ Diterpene hydrocarbon } & 0.1 & \\
\hline \multicolumn{2}{|l|}{ Oxygenated diterpene } & 0.3 & \\
\hline \multicolumn{2}{|l|}{ Phenylpropanoids } & 17.5 & \\
\hline \multicolumn{2}{|c|}{ Long chain oxygenated hydrocarbons } & 29.5 & \\
\hline \multicolumn{2}{|l|}{ Total identified } & 97.1 & \\
\hline
\end{tabular}

$R /$ retention index relative to $C_{8}-C_{25} n$-alkanes on ZB-5 column, $M S$ NIST and Wiley library and the literature, $\mathrm{Cl}$ Co-injection of commercial samples, $t$ trace $(<0.1 \%)$ increased to the visible region which is the property of aromatic organic compound. The result coincides with previous report by Raman and Ramasamy [48].

Melanin pigment plays an important role in cell surface morphology. The loss of pigment biosynthesis leads to extreme changes on the conidial wall orientation. Hence, to further study the effect of JaH extract on cell wall, ergosterol estimation was conducted. Sterols are neutral lipids of eukaryotic cells and play an essential role in the maintenance of cell membrane. Among sterols, ergosterol is the main component of fungal membrane which makes its biosynthetic pathway essential for fungal growth [49]. It is also the primary target for antifungal drug such as Amp B. A marked decrease in the ergosterol percentage was observed in treated conidia in comparison to the wild type conidia (Fig. 2c). The result indicated that $\mathrm{JaH}$ extract reduces the ergosterol production which may lead to changes in membrane fluidity, regulation and distribution of integral membrane proteins.

Cell surface hydrophobicity (CSH) contributes to the interaction between A. fumigatus and the host epithelial cell surface, which is an important factor for spreading infection. It has been reported that there is a direct relation between cell surface hydrophobicity and adherence to the host surface [50-52]. Hence, it can be concluded that decrease in cell surface hydrophobicity would result in decrease in adherence to the host cell surface. Melanin increases both negative charge and hydrophobicity of the conidia. The pigment-less conidia showed decrease in $\mathrm{CSH}$ as compared to the wild type conidia which suggests that blockage of the melanin biosynthetic pathway leads to the reduction of some hydrophobic components on the conidial surface contributing to the marked loss of adherence properties of the conidia. Similar results were reported on the $\Delta p k s P$ strain by Pihet et al. [20].

Melanized conidia have rough outer layer with protrusions on the surface. These conidial protrusions protect the organism from phagocytosis and increase its resistance to ROS produced by phagocytic cells. In the present study, the cell surface morphology of conidia was analyzed using SEM, which clearly indicated loss in cell surface protrusions and showed smooth cell wall conidia in the treated fungus. TEM examination also confirmed protrusion less surface, thinner cell wall and reduced melanin in treated conidia in comparison to control probably due to the progressive detachment of the outermost cell wall layer. Similar results were reported by Jahn et al. and Youngchim et al. [1,53].

The GC-MS analysis of the JaH extract revealed the presence of sabinene, linoleic acid, hexadecanoic acid, safrole, elemicin, myristicin and $\beta$-pinene in varying quantities. Major constituent in essential oil of $M$. 


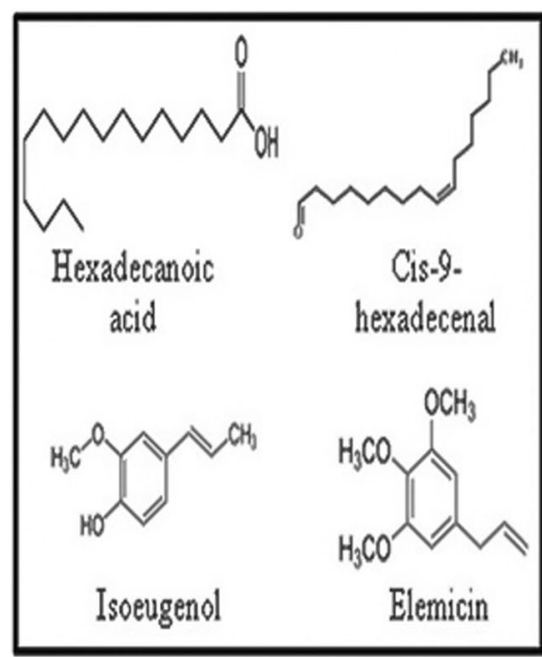

(A)

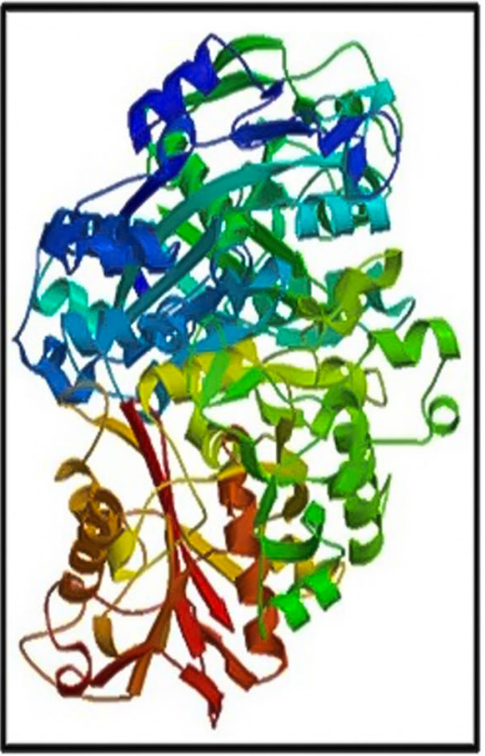

(B)

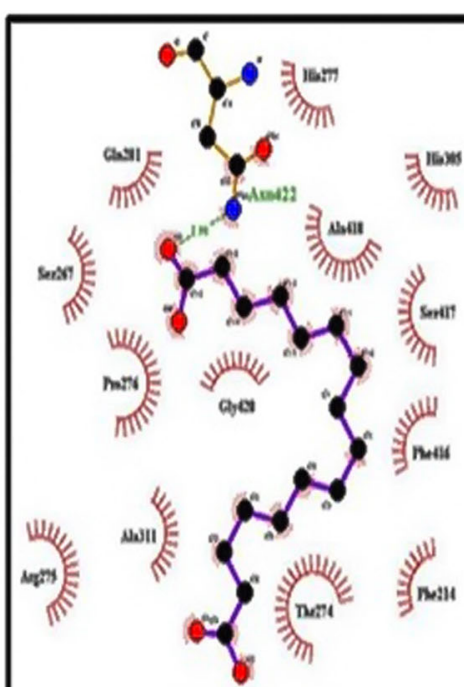

Hexadecanoic acid

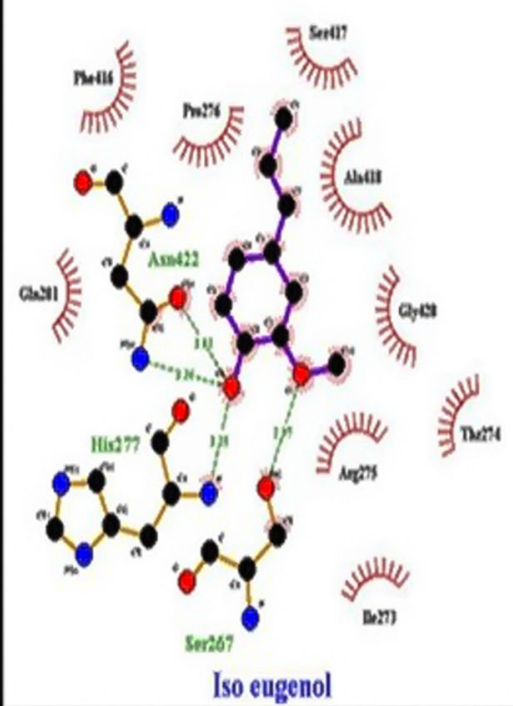

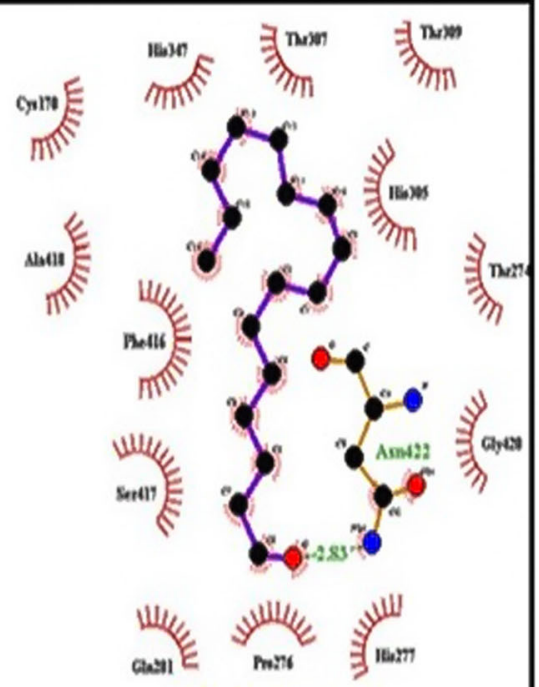

9.Hexadecenal

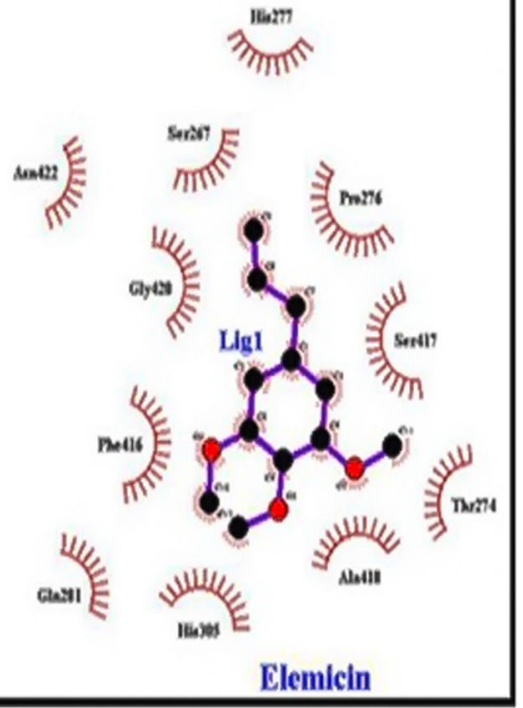

(C)

Fig. 6 Docking study of the compounds with ketosynthase domain of polyketide synthase protein in A. fumigatus. a Structure of hexadecanoic acid, cis-9-hexadecenal, isoeugenol and elemicin, (b) structure of ketosynthase domain of polyketide synthase protein was retrived from Swissmodel, (c) protein- ligand interactions analysed by LigPlot. Dashed lines indicate hydrogen bonds between the atoms involved. The arc with spokes towards the ligand atoms shows the hydrophobic interaction. Hexadecanoic acid, cis-9-hexadecenal and isoeugenol form proper hydrogen bonding whereas elemicin shows hydrophobic interaction only

fragrans are myristicin, safrole, pinene, isoeugenol, 4terpenol as reported by Alcazar-Fuoli and Mellado [54]. Various studies have also reported the presence of neolignan and macelignan in $M$. fragrans extract [14, 42]. The quantitative and qualitative divergence of plant constituents may be due to the geographical, climatic, and soil conditions, which in turn may affect the composition and/or synthesize new secondary metabolites from the same plant species [55]. The potential role of these components needs to be further analyzed.
Ligand-protein interactions can be extrapolated through docking studies. Polyketide synthase is an essential protein for synthesis of conidial pigment melanin. $A$. fumigatus PKS protein contains three important domains: ketosynthase (KS), acyltransferase (AT) and acyl carrier protein (ACP). KS domain is the functionally active site of the enzyme [56]. The KS accepts the acyl unit from the acyl-ACP and condenses malonyl-CoA units shuttled by the ACP onto the starter unit to add a ketide unit [57]. In the present study, structure of KS domain 
of PKSs protein of $A$. fumigatus was modelled for the docking studies with the compounds. The structural differences among the ligands may contribute to differences in the interaction [58]. Based on LigPlot analysis, the $\mathrm{O}$ atom located on the hydrocarbon chain was situated to form $\mathrm{H}$-bonds with Asn422 in the ligands. By contrast, the structural difference in elemicin pushes the same $\mathrm{O}$ atom away from the $\mathrm{H}$-bond forming amino acids, resulting hydrophobic interactions only (Fig. 6c).

\section{Conclusion}

The study concludes that the JaH extract of $M$. fragrans has potential antimelanogenic properties as depicted by inhibition of melanin synthesis, loss in cell surface protrusions, formation of smooth cell wall, reduction in ergosterol concentration and cell surface hydrophobicity. Thus, it can potentially decrease the pathogenicity of $A$. fumigatus and increase its susceptibility to available antifungal drugs. Hence, M. fragrans extract in combination with commonly used antifungals may increase the therapeutic efficacy. This combination approach may be helpful for large number of patients suffering with $A$. fumigatus infections.

\begin{abstract}
Abbreviations
$\triangle p k s$ : Polyketide synthase gene mutant strain; ABPA: Allergic bronchopulmonary aspergillosis; ACP: Acyl carrier protein; Amp B: Amphotericin B; AT: Acyltransferase; CLSI: Clinical and Laboratory Standards Institute; CSH: Cell Surface Hydrophobicity; CzA: Czapek Dox Agar; CzB: Czapek Dox Broth; DHN: 1, 8-dihydroxy naphthalene; DMSO: Dimethyl sulfoxide:; FID: Flame ionization detector; GC-MS: Gas chromatography-mass spectrometer; JaC: Chloroform extract of Myristica fragrans; JaE: Ethanol extract of Myristica fragrans; JaH: Hexane extract of Myristica fragrans: JaM: Methanol extract of Myristica fragrans; KS: Ketosynthase; MEC: Minimum Effective Concentration; PBS: Phosphate buffer saline; PKS: Polyketide synthase; RI: Retention index; ROS: Reactive oxygen species; SEM: Scanning Electron Microscopy; TEM: Transmission Electron Microscopy
\end{abstract}

\section{Acknowledgments}

We would like to thank AIRF- JNU, New Delhi, India for performing transmission electron microscopy.

\section{Authors' contributions}

SH carried out the experimental work, data interpretation and prepared manuscript draft. MV edited and revised the draft. RKJ carried out GC-MS. JS supervised docking study. PV designed the study and supervised the work. All authors have read and approved the final manuscript.

\section{Funding}

This work was financially supported by the DST-SERB in the form of fast track Young scientist (grant no: SB/YS/LS-72/2013), New Delhi, India.

\section{Availability of data and materials}

The datasets used and/or analyzed during the current study will be made available from the corresponding author on reasonable request.

\section{Ethics approval and consent to participate}

Not applicable for this submission.

\section{Consent for publication}

Not applicable for this submission.

\section{Competing interests}

The authors declare that they have no competing interests.

\section{Author details}

Amity Institute of Biotechnology, Amity University Uttar Pradesh, Noida 201301, India. ${ }^{2}$ Department of Phytochemistry, National Institute of Traditional Medicine, Indian Council of Medical Research, Nehru Nagar, Belagavi, Karnataka 590010, India. ${ }^{3}$ Genomic Laboratory, Department of Biotechnology and Bioinformatics, Jaypee University of Information Technology, Solan, Himachal Pradesh 173212, India.

Received: 20 July 2018 Accepted: 20 February 2020

Published online: 02 March 2020

\section{References}

1. Jahn B, Koch A, Schmidt A, Wanner G, Gehringer H, Bhakdi S, et al. Isolation and characterization of a pigmentless-conidium mutant of Aspergillus fumigatus with altered conidial surface and reduced virulence. Infect Immun. 1997:65:5110-7.

2. Thakur R, Anand R, Tiwari S, Singh AP, Tiwary BN, Shankar J. Cytokines induce effector T-helper cells during invasive Aspergillosis; what we have learned about T-helper cell? Front Microbiol. 2015;6:1-6.

3. Latge JP. The pathobiology of Aspergillus fumigatus. Trends Microbiol. 2001; 9:382-9.

4. Walsh TJ, Anaissie EJ, Denning DW, Herbrecht R, Kontoyiannis DP, Marr KA, et al. Treatment of Aspergillosis: clinical practice guidelines of the infectious diseases society of America. Clin Infect Dis. 2008:46:327-60.

5. Gallis HA, Drew RH, Pickard WW. Amphotericin B: 30 years of clinical experience. Rev Infect Dis. 1990;12:308-29.

6. Arnold TM, Dotson E, Sarosi GA, Hage CA. Traditional and emerging antifungal therapies. Proc Am Thorac Soc. 2010;7:222-8.

7. Arif T, Bhosale JD, Kumar N, Mandal TK, Bendre RS, Lavekar GS, et al. Natural products- antifungal agents derived from plants. J Asian Nat Prod Res. 2009; 11:621-38.

8. Arora DS, Kaur J. Antimicrobial activity of spices. Int J Antimicrob Agents. 1999:12:257-62.

9. Gumus T, Demirci AS, Sagdic O, Arici M. Inhibition of heat resistant molds: Aspergillus fumigatus and Paecilomyces variotii by some plant essential oils. Food Sci Biotechnol. 2010;19:1241-4.

10. Satish S, Mohana DC, Ranhavendra MP, Raveesha KA. Antifungal activity of some plant extracts against important seed borne pathogens of Aspergillus sp. J Agric Technol. 2007:3:109-19.

11. Suleiman MM, McGaw L, Naidoo V, Eloff JN. Evaluation of several tree species for activity against the animal fungal pathogen Aspergillus fumigatus. South Afr J Botany. 2010;76:64-71.

12. Witkowska AM, Hickey DK, Alonso-Gomez M, Wilkinson M. Evaluation of antimicrobial activities of commercial herb and spice extracts against selected food-borne bacteria. J Food Res. 2013;2:37-54.

13. Pooja V, Sanwal H, Goyal A, Bhatnagar S, Srivastava AK. Activity of Myristica fragrans and its effect against filamentous and non-filamentous fungus. Int J Pharm Pharm Sci. 2012;4:538-40.

14. Yang XW, Huang X, Ahmat M. New neolignan from seed of Myristica fragrans. Zhongguo Zhong Yao Za Zhi. 2008;33:397-402.

15. Sahar SH, Nagaraju B, Bolouri A, Zothanmawia C, Hossein N, Kushnoor NZ, et al. Anxiolytic effect of Myristica fragrans. J Harmo Res Pharm. 2013;2:1723

16. Green RC. Nutmeg poisoning. JAMA. 1959;177:1342-4.

17. Panayotopoulos DJ, Chisholm DD. Hallucinogenic effect of nutmeg. Br Med J. 1970;1:754.

18. Jaiswal $P$, Kumar P, Singh VK, Singh DK. Biological effects of Myristica fragrans. Annu Rev Biomed Sci. 2009;11:21-9.

19. Shankar J. An overview of toxins in Aspergillus associated with pathogenesis. Int J Life Sci Biotechnol Pharm Res. 2013;2:16-31.

20. Pihet M, Vandeputte $P$, Tronchin G, Renier G, Saulnier P, Georgeault S, et al. Melanin is an essential component for the integrity of the cell wall of Aspergillus fumigatus conidia. BMC Microbiol. 2009;9:177-88.

21. Jacobson ES. Pathogenic roles for fungal melanins. Clin Microbiol Rev. 2000; 13:708-17.

22. Nosanchuk JD, Casadevall A. Impact of melanin on microbial virulence and clinical resistance to antimicrobial compounds. Antimicrob Agents Chemother. 2006;50:3519-28.

23. Brakhage AA, Liebmann B. Aspergillus fumigatus conidial pigment and CAMP signal transduction: significance for virulence. Med Mycol. 2005;43:S75-82. 
24. Raaman N. Qualitative phytochemical screening. In: Phytochemical Techniques. New Delhi: New India Publishing Agency; 2006. p. 19-24.

25. Clinical and Laboratory Standards Institute (CLSI). Reference method for broth dilution testing of filamentous fungi. 2nd ed. Wayne: CLSI; 2008. CLSI document M38-A2.

26. Rajagopal K, Kathiravan G, Karthikeyan S. Extraction and characterization of melanin from Phomopsis: A phellophytic fungi isolated from Azadirachta indica A. Juss. Afr J Microbiol Res. 2011;5:762-6.

27. Lee JK, Jung HM, Kim SY. 1, 8-Dihydroxynaphthalene (DHN)-melanin biosynthesis inhibitors increase erythritol production in torula corallina, and DHN-melanin inhibits erythrose reductase. Appl Environ Microbiol. 2003;69: 3427-34.

28. Pal AK, Gajjar DU, Vasavada AR. DOPA and DHN pathway orchestrate melanin synthesis in Aspergillus species. Med Mycol. 2014;52:10-8.

29. Young LY, Hull CM, Heitman J. Disruption of ergosterol biosynthesis confers resistance to amphotericin B in Candida lusitaniae. Antimicrob Agents Chemother. 2003:47:2717-24.

30. Kennedy MJ, Rogers AL, Hanselmen LR, Soll DR, Yancey RJ. Variation in adhesion and cell surface hydrophobicity in Candida albicans white and opaque phenotypes. Mycopathologia. 1988;102:149-56.

31. Graham L, Orenstein JM. Processing tissue and cells for transmission electron microscopy in diagnostic pathology and research. Nat Protoc. 2007; 2:2439-50.

32. Joshi RK. Chemical composition of Leucas stelligera. Chem Nat Compd. 2015; 51:500-50.

33. Joshi RK. E, E-a-Farnesene rich essential oil of Saraca asoca (Roxb.) wild flower. Nat Prod Res. 2016;30:979-81.

34. Joshi RK. GC/MS analysis of the essential oil of Leucas indica from India. Nat Prod Commun. 2014;9:1607-8.

35. Joshi RK. Leucas aspera (wild.) link essential oil from India: $\beta$-Caryophyllene and 1-octen-3-ol chemotypes. J Chromatogr Sci. 2015;54:295-8.

36. Adams RP. Identification of essential oil components by gas chromatography/mass spectroscopy. 4th ed. Carol Stream: Allured Publication Corporation; 2007.

37. McFadden DC, Casadevall A. Capsule and melanin synthesis in Cryptococcus neoformans. Med Mycol. 2001;39:19-30.

38. Cowan MM. Plant products as antimicrobial agents. Clin Microbiol Rev. 1999;12:564-82.

39. Iloki-Assanga SB, Lewis-Luján LM, Lara-Espinoza CL, Gil-Salido AA, Fernandez-Angulo D, Rubio-Pino JL. Solvent effects on phytochemical constituent profiles and antioxidant activities, using four different extraction formulations for analysis of Bucida buceras L. and Phoradendron californicum. BMC Res Notes. 2015;8:396-28.

40. Rudd D, Benkendorff K, Voelcker NH. Solvent separating secondary metabolites directly from biosynthetic tissue for surface-assisted laser desorption ionisation mass spectrometry. Mar Drugs. 2015;13:1410-31.

41. Asgarpanah J, Kazemivash N. Phytochemistry and pharmacologic properties of Myristica fragrans Hoyutt: A review. Afr J Biotechnol. 2012;11:12787-93.

42. Iyer M, Gujjari AK, Gowda V, Angadi S. Antifungal response of oralassociated candidal reference strains (American type culture collection) by supercritical fluid extract of nutmeg seeds for geriatric denture wearers: an in vitro screening study. J Indian Prosthodont Soc. 2017;17:267-72.

43. Suhr Kl, Nielsen PV. Antifungal activity of essential oils evaluated by two different application techniques against rye bread spoilage fungi. J Appl Microbiol. 2003;94:665-74.

44. Dhingra D, Sharma A. Antidepressant-like activity of $n$-hexane extract of nutmeg (Myristica fragrans) seeds in mice. J Med Food. 2006;9:84-9.

45. Kamble VA, Patil SD. Spice-derived essential oils: effective antifungal and possible therapeutic agents. Int J Geogr Inf Syst. 2008;14:129-43.

46. Sanford KJ, Heinz DE. Effects of storage on the volatile composition of nutmeg. Phytochemistry. 1971;10:1245-50.

47. Valente VMM, Jham GN, Jardim CM, Dhingra OD, Ghiviriga I. Major antifungals in nutmeg essential oil against Aspergillus flavus and $A$ ochraceus. J Food Res. 2015;4:51-7.

48. Raman NM, Ramasamy S. Genetic validation and spectroscopic detailing of $\mathrm{DHN}$-melanin extracted from an environmental fungus. Biochem Biophys Rep. 2017;12:98-107.

49. Eisenman HC, Casadevell A. Synthesis and assembly of fungal melanin. Appl Microbiol Biotechnol. 2012;93:931-40
50. Pan WH, Li PL, Liu Z. The correlation between surface hydrophobicity and adherence of Bifidobacterium strains from centenarians' faeces. Anaerobe. 2006;12:148-52.

51. Samaranayake YH, Samaranayak LP. Relationship between the cell surface hydrophobicity and adherence of Candida krusei and Candida albicans to epithelial and denture acrylic surfaces. Apmis. 1995;103:707-13.

52. Vishwas SK, Bhat G, Kamath A, Shivnanda PG. Effect of trace elements on surface hydrophobicity and adherence to Escherichia coli to uroepithilial cells. Indian J Exp Biol. 2004;42:681-5.

53. Youngchim S, Morris-Jones R, Hay RJ, Hamilton AJ. Production of melanin by Aspergillus fumigatus. J Med Microbiol. 2004;53:175-81.

54. Alcazar-Fuoli L, Mellado E. Ergosterol biosynthesis in Aspergillus fumigatus: its relevance as an antifungal target and role in antifungal drug resistance. Front Microbiol. 2012;3:439-48.

55. Forrest JE, Heacock RA. Identification of the major components of the essential oil of mace. J Chromatogr. 1972;69:115-21.

56. Bhetariya PJ, Prajapati M, Bhaduri A, Mandal RS, Varma A, Madan T, et al. Phylogenetic and structural analysis of polyketide synthases in Aspergilli. Evol Bioinform Online. 2016;12:109-19.

57. Crawford JM, Townsend TA. New insights into the formation of fungal aromatic polyketides. Nat Rev Microbiol. 2010;8:879-89.

58. Tou W, Chang S, Lee C, Chen CY. Drug design for neuropathic pain regulation from traditional Chinese medicine. Sci Rep. 2013;3:1-13.

\section{Publisher's Note}

Springer Nature remains neutral with regard to jurisdictional claims in published maps and institutional affiliations.
Ready to submit your research? Choose BMC and benefit from:

- fast, convenient online submission

- thorough peer review by experienced researchers in your field

- rapid publication on acceptance

- support for research data, including large and complex data types

- gold Open Access which fosters wider collaboration and increased citations

- maximum visibility for your research: over $100 \mathrm{M}$ website views per year

At $\mathrm{BMC}$, research is always in progress.

Learn more biomedcentral.com/submissions 